\title{
LAS VARIANTES DE FIJO EN ESPAÑOL COMO MARCAS EPISTÉMICAS: ESTUDIO DIACRÓNICO DE SU DISTRIBUCIÓN Y USO ${ }^{1}$
}

\author{
THE VARIANTS OF FIJO AS EPISTEMIC MARKS IN SPANISH: \\ DIACHRONIC STUDY OF ITS DISTRIBUTION AND USE
}

\author{
RUTH M. LAVALE-ORTIZ \\ Universidad de Alicante \\ ruth.lavale@ua.es
}

\section{RESUMEN}

En este trabajo se analizan desde el punto de vista diacrónico las variantes léxicas de fijo con valor epistémico en español. El estudio lexicográfico y de corpus que se ha realizado ha permitido descubrir 18 formas que tienen como base el adjetivo fijo y que muestran, como hilo conductor, valores propios de la modalidad epistémica y de la evidencialidad, aunque con claras diferencias entre ellas. Estas variantes han sido buscadas en los tres corpus de la Real Academia Española y el análisis de las ocurrencias disponibles para cada una de ellas ha permitido distinguir contextos de aparición recurrentes, básicos en el proceso de rutinización de las unidades epistémicas, y una distribución especial para cada forma dependiendo de diversos factores: principalmente, el dialecto, la vitalidad y el registro. El estudio demuestra que la lengua no crea formas léxicas semejantes de manera arbitraria, sino que cada una se especializa en representar los contenidos desde una determinada perspectiva y en expresar la realidad con diferentes matices.

Palabras clave: Modalidad epistémica, evidencialidad, variación, Lingüística Cognitiva.

\section{ABSTRACT}

In this paper the lexical variants of fijo with epistemic value in Spanish are analyzed diachronically. The lexicographic and corpus study that has been carried out has allowed to discover 18 forms that have as base the adjective fijo and that show values of epistemic modality and evidentiality as a guiding thread, although with clear differences among them. These variants have been searched in the three corpus of the Spanish Royal Academy and the analysis of the available occurrences for each of them has allowed to distinguish recurrent contexts of appearance, as the process of routinization of the epistemic units

\footnotetext{
${ }^{1}$ Este trabajo se enmarca en los proyectos de investigación GRE14-08 y GV/2015/113.
} 
states, and a special distribution for each form depending on dialect, vitality and register mainly. The study shows that the language does not create similar lexical forms in an arbitrary way, but each one specializes in representing the contents from a certain perspective and in expressing the reality with different nuances.

Keywords: Epistemic modality, evidentiality, variation, Cognitive Linguistics.

Recibido: 28/04/2018. Aceptado: 15/03/2019.

\section{INTRODUCCIÓN}

- $l$ objetivo principal de este trabajo es analizar la variación que se produce en la Emarcación epistémica de las formas que tienen como base la palabra fijo. De acuerdo con la RAE (2009, pp. 2376-2377), algunas locuciones adverbiales poseen "VARIANTES LÉXICAS, a menudo usadas en áreas geográficas distintas y, a veces, también en épocas diferentes". Una de esas marcas que se caracterizan por su variedad es fijo, que, según la Academia, cuenta con las formas dialectales a la fija, en fija y de fija, propias de zonas hispanoamericanas, con la variante en fijo, que ha dejado de emplearse en español peninsular, y con de fijo, como la forma más frecuente hoy en día en todo el español; a pesar de esta variedad, todas estas locuciones comparten el significado de 'con seguridad, con certeza'. Sin embargo, la variación que presentan las marcas epistémicas que toman como base la forma fijo es mucho más amplia: fuera de esta nómina de cinco elementos, el análisis de corpus que se presenta en este estudio demuestra la existencia de un abanico extenso de formas que comparten ese significado común pero que se comportan como locuciones conjuntivas, marcadores discursivos, locuciones verbales y expresiones fijas. Este rico paradigma le permite al hablante mostrar su actitud firme y segura ante lo dicho, pero su elección por una u otra forma no parece ser en absoluto arbitraria. En este trabajo se comprobará que el hecho de que el hablante elija una u otra variante puede deberse a la zona dialectal en la que se encuentra o a usos más actuales frente a otros que han dejado de emplearse, pero también a diferencias que obedecen al registro y a la expresión de matices semánticos que le permiten conceptualizar la escena que desea presentarle al interlocutor de una u otra manera.

El elemento común en estas variantes es el adjetivo fijo, que tiene su origen en el participio de pasado del verbo figere 'clavar' con el significado de 'clavado', 'fijo' (Corominas y Pascual, 1980), 'firme, asegurado, clavado' (Cuervo, 1998). Como se demostró en otro estudio diacrónico (Lavale-Ortiz, en prensa), el proceso de gramaticalización (Company, 2004, pp. 37-40) de esta forma se desarrolla en tres etapas. En un primer estadio, fijo posee valor léxico local: el hablante observa una escena en la que una entidad está en una posición estable y firme en un espacio físico. Con este valor, se comporta como adjetivo (1) y como adverbio con el verbo mirar (2): 
(1) Manet esta fixo \& quedo (CORDE. Palencia, Alfonso de. [1490] 1992. Universal vocabulario en latín y en romance. Madison, Estados Unidos: Hispanic Seminary of Medieval Studies).

(2) Ánima devota, que en el signo / e santo nonbre estás contenplando, / e los sus rayos con viso aquilino / solares miras fixo, non vagando (CORDE. Marqués de Santillana (López de Mendoza, Ínigo). [1438-55] 1988. Sonetos al itálico modo. Barcelona, España: Planeta, 75).

En un segundo estadio, fijo deja de modificar a entidades físicas localizadas en espacios externos y pasa a expresar, por un proceso de interiorización, que una entidad más abstracta queda localizada de manera 'firme, clavada o estable' en el plano personal del hablante, por lo que algo queda 'fijo en mí, en mi interior', como sucede en (3):

(3) lo qual su Alteza syenpre ha tenido e tiene fixo en su memoria, con deseo de honrrar y engrandesçer estos Reynos (CORDE. Anónimo. [1523] 1882. Cortes de Valladolid de 1523. Madrid, España: Real Academia de la Historia).

En el último estadio del proceso de gramaticalización, fijo abandona el plano personal y la función adjetival y actúa en el plano discursivo como adverbio (4) o marcador discursivo (5); es aquí donde se enmarca el resto de variantes con valor epistémico, que actúan con las funciones anteriores o como locuciones adverbiales (6) y conjuntivas (7), y con estas funciones más gramaticales el hablante expresa que algo es 'fijo para él', por lo que la marca epistémica, que ha sufrido un proceso de subjetivación (véase el epígrafe 3), le sirve al hablante para volcar su compromiso personal con la certeza de lo dicho.

(4) Irme tras de ti elijo; / que en Compañía que las armas usa, / la silla tendré fijo, / sin que mi justa quede por confusa (CORDE. Espinosa, Pedro de. [1590-1650] 1975. Poesías. Madrid, España: Espasa-Calpe, 75-76).

(5) -Pues bien, ahora va usted a oír todo lo que yo he hecho y conocerá usted si soy su amiga. Hace mucho tiempo que sé que esa mujer de Barracas vive muy retirada, $y$, por consiguiente, debe ser unitaria.

¡¡Oh, quién sabe!

-No, unitaria, fijo.

-Bien, prosiga usted (CORDE. Mármol, José. [1851-1855] 2000. Amalia. Madrid, España: Cátedra, 424).

(6) Y aunque siendo el testimonio dado en 1542 devía ponerse antes, no se ha hecho por no constar a punto fixo la data de la concesion (CORDE. Tobar, Baltasar de. [1695] 1954. Compendio bulario índico. Sevilla, España: CSIC-Escuela de Estudios Hispanoam. Sevilla, 301). 
(7) Bien lexos de evacuarse por la aplicación de sanguijuelas la sangre más gruessa y pesada, es fixo que, si en la sangre evacuada por esse medio hai alguna diferencia de la que se extrahe por la lanceta, aquella ha de ser más tenue y ligera que esta (CORDE. Feijoo, Benito J. [1739] 2003. Theatro Crítico Universal. Madrid, España: RAE, 246).

El paso a dominios cada vez más abstractos por parte de fijo y sus variantes, de lo físico-local a lo nocional (primero en el plano personal del hablante y en un segundo momento como exteriorización de su visión subjetiva hacia el discurso), se explica por procedimientos metafóricos y metonímicos (Lakoff y Johnson, 1980). Así, en un primer paso se aplica la metáfora LA MENTE ES EL CUERPO, por la que se extiende el dominio físico en el que un agente deja de manera anclada una entidad al dominio conceptual en el que un agente o experimentador asienta o ancla una idea o concepto. El segundo paso se explica por metonimia: si una idea o concepto está firme o clavado, estará estable y será inamovible y, en el ámbito argumentativo, lo inamovible es lo cierto, lo indudable, lo que es más fuerte y está intensificado. Por último, entra en juego la metáfora LA CERTEZA ES UNA FUERZA, por la que se entiende que, si en el dominio físico las entidades que son firmes y estables son robustas, más fuertes y resisten al movimiento, en el dominio conceptual lo que es cierto, seguro e indudable resiste al fluir discursivo y es argumentativamente más fuerte. En definitiva, el concepto de fuerza es la base de la evolución semántica de esta unidad, ya se interprete como fijación física o como seguridad y anclaje cognitivo.

Tras esta breve introducción, el artículo se organiza en cuatro apartados. En primer lugar, se detalla cuáles son las variantes de fijo que se han documentado en las obras lexicográficas así como otras formas que se han descubierto en el análisis de corpus; asimismo, se comenta el corpus utilizado para el estudio de estas variantes. En segundo lugar, se introduce el contenido general que aportan estas marcas: la modalidad epistémica y la evidencialidad. En tercer lugar, se analizan las variantes de fijo conjugando diversos parámetros (dialectales, diafásicos, usos anacrónicos, funciones desempeñadas y rasgos semánticos aportados) para establecer cuáles son sus diferencias en el uso. Finalmente, se aúnan los resultados en las conclusiones.

\section{DOCUMENTACIÓN LEXICOGRÁFICA Y CORPUS DE TRABAJO DE LAS VARIANTES DE FIJO}

Como se ha señalado en la introducción, la primera búsqueda efectuada en el corpus diacrónico de la RAE reveló que el número de variantes léxicas de fijo como marca epistémica era superior a esa relación inicial anunciada en RAE (2009). Por este motivo, y con la finalidad de determinar cuántas estructuras formaban parte de esta familia, se realizó un repaso de las obras lexicográficas monolingües inclui- 
das en el Nuevo tesoro lexicográfico de la lengua española y de otras obras posteriores, como las versiones más recientes del diccionario académico o el Diccionario de partículas discursivas del español (Briz, Pons y Portolés, 2008), entre otros. Este trabajo de búsqueda se resume en la Tabla I, donde puede observarse cuál es la primera documentación lexicográfica de cada variante epistémica de fijo:

Tabla I. Primera documentación lexicográfica de fijo y sus variantes léxicas con valor epistémico.

\begin{tabular}{|c|c|}
\hline Variante de fijo & Primera documentación lexicográfica \\
\hline a la fija & RAE S (1970): 'm. adv. Chile y Urug. Con seguridad' \\
\hline a punto fixo/fijo & $\begin{array}{l}\text { Domínguez (1853): 'mod. adv. Á punto fijo: fijamente, á ciencia } \\
\text { cierta' }\end{array}$ \\
\hline de fija & RAE (2009): variante léxica de fijo en el Río de la Plata \\
\hline de fija que & No registrada \\
\hline de fijo/fixo & Gaspar y Roig (1853): 'fr.: A PUNTO FIJO o DE FIJO: con seguridad' \\
\hline de fijo que & $\begin{array}{l}\text { Briz, Pons y Portolés (2008): variante de fijo (que): 'aumenta el } \\
\text { grado de certeza o veracidad que el hablante otorga a lo dicho' }\end{array}$ \\
\hline en fija & RAE S (1970): 'm. adv. Argent. y Urug. Con seguridad' \\
\hline en fijo & RAE (2001): 'loc. adv. rur. Arg. de fijo' \\
\hline en fijo que & No registrada \\
\hline ésa es la fija & $\begin{array}{l}\text { RAE U (1925): 'fr. fam. con que se aprueba como cierta alguna } \\
\text { cosa' }\end{array}$ \\
\hline ésta es la fija & $\begin{array}{l}\text { RAE U (1925): 'fr. que indica haber llegado ya la ocasión de que } \\
\text { ocurra aquello que se teme o se espera' }\end{array}$ \\
\hline estar en lo fijo & Cuervo (1998): 'estar en lo cierto'² \\
\hline fixo/fijo & RAE (1732): 'firme, segúro y cierto' \\
\hline fijo que & Salamanca (1996): ' $a d v$. modo 5 Con certeza o seguridad' \\
\hline $\begin{array}{l}\text { ir (alguien) a } \\
\text { la fija }\end{array}$ & RAE (2001): 'loc. verb. Col. y Nic. Ir sobre seguro' \\
\hline por fijo/fixo & No registrada \\
\hline ser fijo/fixo & Cuervo (1998): 'ser seguro'³ \\
\hline ser fixo/fijo que & No registrada \\
\hline
\end{tabular}

${ }^{2}$ Las búsquedas en los corpus consultados no han reportado datos de esta construcción. Únicamente se cuenta con el ejemplo de P. Baroja aportado por Cuervo: “¿Cuál de los tres relojes estaba en lo fijo? ¿Cuál de aquellas tres máquinas para medir el tiempo tenía más exactitud en sus indicaciones?”. Por su nula presencia, se ha descartado esta forma en el análisis.

${ }^{3}$ En realidad, Cuervo recoge la forma ser fijo con este valor, pero emplea ejemplos de es fijo que. 
Una vez establecido el conjunto de variantes léxicas que iban a conformar el objeto de estudio, se analizaron ejemplos reales de esas formas para comprobar, como indicaba la Academia, que diferían en su distribución geográfica y temporal, esto es, que muchas de esas expresiones se diferenciaban por su empleo en distintas variedades dialectales y en distintas épocas del español. En cuanto al momento temporal en el que aparece cada una de estas variantes, el estudio realizado en el CORDE para establecer las primeras ocurrencias en lengua escrita con valor epistémico ha permitido configurar la siguiente línea cronológica:
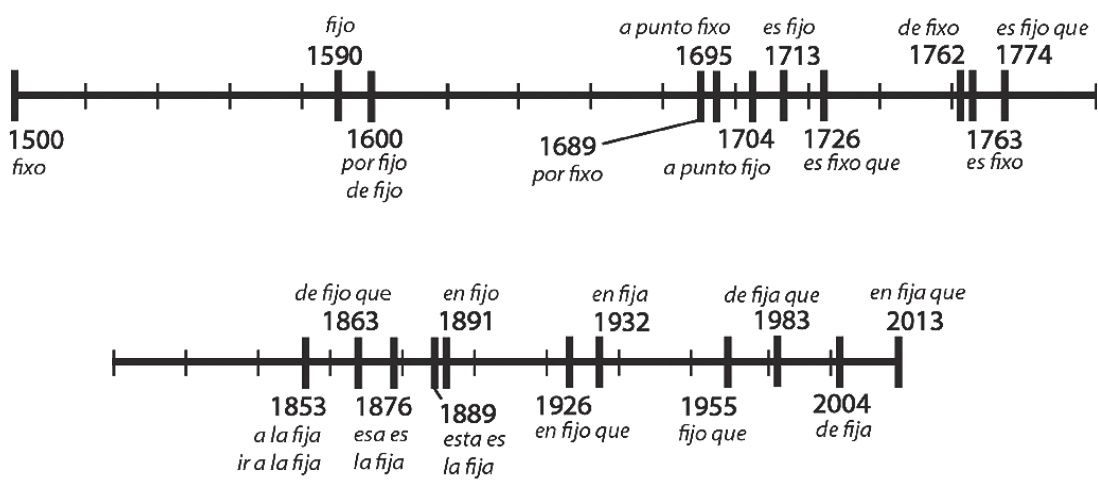

Figura 1. Línea cronológica de los primeros usos epistémicos de las variantes de fijo.

En esta línea cronológica se puede comprobar la variedad de estructuras que se han ido creando con el paso del tiempo sobre la base fijo y que comparten la expresión de contenidos epistémicos. Tal y como puede observarse, los usos epistémicos empiezan a registrarse en los inicios del siglo XVI con la forma básica fijo empleada como adverbio y, a partir de este momento, comienzan a desarrollarse nuevas formas complejas, manifestadas como marcadores discursivos, locuciones adverbiales, conjuntivas o verbales y expresiones más fijas que codifican ese mismo valor.

Con la finalidad de contar con un panorama general y completo de la evolución de cada una de estas formas léxicas desde los inicios del idioma hasta la actualidad, se ha realizado una búsqueda en los tres corpus que ofrece la RAE: el CORDE, que recoge textos desde los inicios del español hasta el 1974; el CREA, compuesto por textos datados desde 1975 y hasta el 2004; y el CORPES XXI, que contiene textos entre 2001 y 2012. No obstante, en los casos en los que la variante estudiada no tuviera suficiente presencia en estos bancos de datos o se tratara de una forma marcadamente dialectal, se ha realizado una búsqueda adicional en el 
subcorpus "Web/Dialectos" del Corpus del Español (en adelante, CDE), formado por textos de español contemporáneo, por si este banco de datos reportaba más datos sobre su uso.

Una vez configurado este corpus de ejemplos, se han analizado todas las ocurrencias de las variantes léxicas de fijo y han sido clasificadas en una base de datos atendiendo a diferentes parámetros establecidos a partir de tres fuentes básicas. En primer lugar, se partió de las precisiones teóricas sobre la evidencialidad (véase el epígrafe 3) y se analizó cómo cada una de las variantes expresaba tanto la perspectiva desde la que se muestra lo dicho (la persona) como el modo de adquisición de la información, la fuente de la que surge y el acceso a la información. En segundo lugar, la lectura de las ocurrencias del corpus permitió comprobar que había características relacionadas con el uso de estas variantes que era interesante tener en cuenta como parámetros de análisis. Así, se precisó que era necesario atender a los siguientes aspectos: la posición que ocupa la marca epistémica en el enunciado y la presencia o ausencia de pausas; el tiempo verbal utilizado; su orientación y función; y los contextos de aparición más frecuentes que han favorecido la adquisición de valor epistémico. En tercer lugar, no se olvidaron los factores vinculados al lugar en el que aparecen esos contextos: el género textual y la variedad diatópica. A diferencia de los parámetros señalados en primer lugar, los parámetros relacionados con el uso concreto de las formas (los del segundo y tercer grupo) fueron surgiendo a medida que se realizaba el análisis, lo que amplió de manera considerable los datos iniciales de la base de datos. A pesar de la diversidad encontrada en los ejemplos, el establecimiento de estos parámetros comunes ha logrado obtener un análisis homogéneo y coherente de los datos, como se comprobará en el epígrafe 4.

\section{LA MODALIDAD EPISTÉMICA Y LA EVIDENCIALIDAD}

El proceso de cambio semántico apuntado para fijo y sus variantes es un caso paradigmático de la actuación del mecanismo de subjetivación. De acuerdo con este procedimiento, las unidades lingüísticas van perdiendo el contenido léxico que las caracteriza en determinados contextos porque el hablante comienza a volcar en ellas su perspectiva subjetiva, su actitud frente a lo dicho (Traugott, 1995, p. 31). Para lograr este cambio, las unidades lingüísticas, que tienen un significado léxico, empiezan a aparecer de manera reiterada en ciertos contextos, esto es, tiene lugar el proceso de rutinización explicado por Haiman (1994, p. 3), con el que se logra la convencionalización de una serie de implicaturas conversacionales que acaban asociándose a esas unidades y se activan incluso en situaciones en las que los elementos contextuales con los que solían aparecer no están presentes. Por lo tanto, el significado pragmático que adquieren las unidades en este proceso es progresivo, contextualizado y, finalmente, convencionalizado. 
Fijo y sus variantes han codificado en este proceso matices pragmáticos muy concretos: la modalidad epistémica y la evidencialidad. Las variantes de fijo son marcas epistémicas porque se emplean para "hacer referencia a las creencias del hablante y a los compromisos que adopta con respecto a la veracidad de un contenido proposicional", evaluando "la credibilidad o verosimilitud que el hablante concede a un juicio" (Rodríguez-Espiñeira, 2010, p. 186). Con estas marcas, el hablante muestra un compromiso fuerte en la certeza de lo afirmado, refuerza lo dicho, lo intensifica y lo presenta como un elemento al que el interlocutor debe prestar una atención especial puesto que en él está volcando un compromiso personal. Asimismo, las variantes de fijo codifican la fuente de la evaluación y del conocimiento sobre lo dicho, esto es, muestran un contenido evidencial. Siguiendo a Bermúdez (2005, pp. 10-18), la evidencialidad es una categoría que se define gracias a tres dimensiones de carácter continuo: el modo de adquisición de la información, que puede realizarse de manera sensorial (testigo presencial) o de manera cognitiva, por inferencias, razonamientos o conjeturas; la fuente de la información, que puede ser personal o ajena; y el acceso a la información, que puede ser privativo o universal, es decir, compartido en la comunidad (el folklore). Con esta información, el hablante trata de trasladarle a su interlocutor que la información que presenta es fiable (porque él lo ha visto o porque alguien se lo ha contado) y debe confiar en su veracidad.

Gracias a la información que codifican, cuando el interlocutor escucha un enunciado modalizado con fijo o sus variantes entiende que la veracidad de su contenido viene avalada por el compromiso del hablante, que ante ese enunciado debe quedarse inmóvil y firme (retomando el sentido etimológico de fijo), que es un elemento fuerte porque destaca y resiste (elemento de anclaje) al desarrollo discursivo y que debe compartir el grado de creencia en lo dicho porque, de acuerdo con los principios conversacionales, se desea que la conversación prospere y que se creen vínculos entre los interlocutores en forma de un convencimiento compartido sobre la veracidad del contenido presentado.

El estudio diacrónico realizado sobre las variantes léxicas que tienen como base el elemento fijo demuestra que estas formas han experimentado un proceso de subjetivación por el que han gramaticalizado contenidos pragmáticos gracias a su presencia reiterada en determinados contextos. Desde la perspectiva del hablante son marcas epistémicas y, en consecuencia, subjetivas, con las que se desea estrechar lazos con el receptor. Desde el punto de vista del oyente son, sin duda, unidades de anclaje cognitivo y señales que favorecen la interconstrucción (Bermúdez, 2005, p. 28) del significado y el paso de la subjetivación a la intersubjetivación ${ }^{4}$. En realidad, los cambios experimentados por fijo y sus variantes parecen demostrar la

${ }^{4}$ Para una revisión actualizada de los conceptos de subjetivación, gramaticalización, intersubjetivación y otros procesos relacionados, véase Cifuentes Honrubia (2018). 
hipótesis de Narrog (2017) sobre las secuencias del cambio semántico: inicialmente, el elemento léxico con significado concreto sufre un proceso de subjetivación $\mathrm{u}$ orientación al hablante por el que muestra su actitud y funciona en dominios gramaticales con significados más abstractos; posteriormente, surgen los valores intersubjetivos, con los que estas marcas se orientan al oyente, puesto que son una muestra de la atención que se le presta al receptor y sirven para establecer lazos entre los interlocutores, y los valores orientados al propio discurso, en el sentido de que se emplean para la construcción del propio discurso, integran las partes de lo dicho y dan coherencia al texto.

\section{EL REPARTO DE CONTEXTOS: USO Y ESPECIALIZACIÓN DE LAS VARIANTES DE $F I J O$}

En los siguientes epígrafes se muestra el análisis de las diferentes variantes de fijo con valor epistémico. En el Gráfico 1, que presenta el número de ocurrencias encontradas de cada una de las estructuras, puede observarse de manera visual la extensión en el uso de estas marcas:

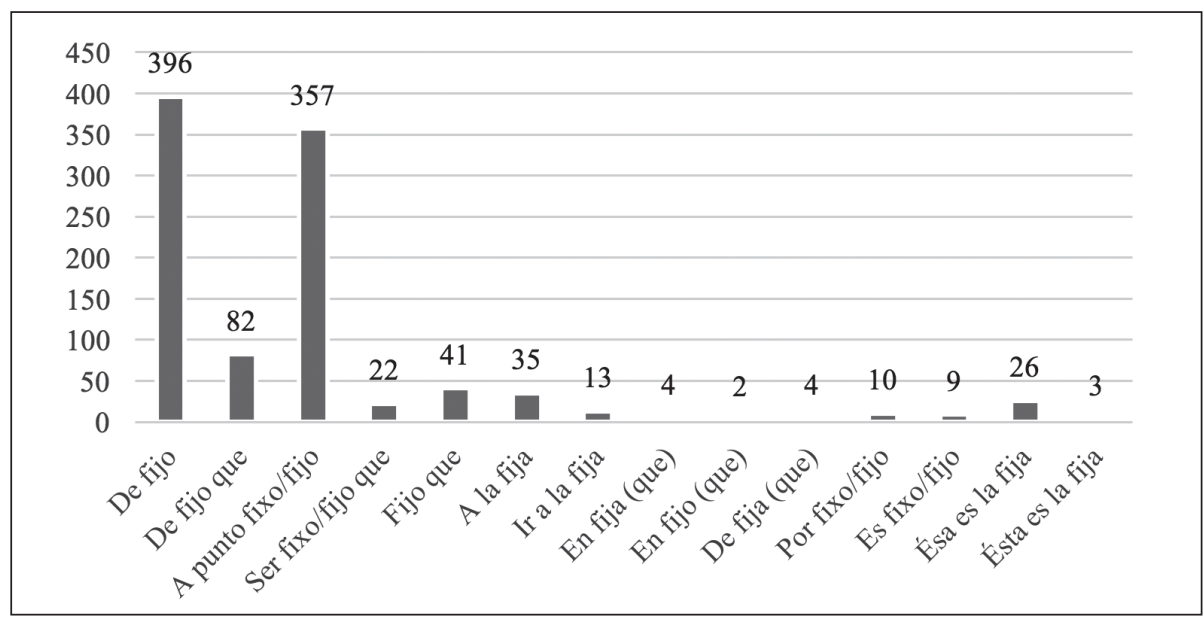

Gráfico 1. Extensión en el uso de las variantes de fijo.

$\mathrm{Al}$ ahondar en la información sobre el uso de estas formas que proporcionan las ocurrencias del corpus (y que quedarán expuestas con detalle en los siguientes epígrafes para cada una de las variantes), es posible obtener una visión general de datos comunes como el uso geográfico y los géneros textuales más habituales en los que se documentan: 
Tabla II. Uso dialectal y procedencia textual más frecuente de las variantes de fijo.

\begin{tabular}{|c|c|c|c|c|c|c|}
\hline & \multicolumn{2}{|c|}{ Dialecto } & \multicolumn{4}{|c|}{ Género textual } \\
\hline & Peninsular & América & Narrativa & $\begin{array}{c}\text { Histórico- } \\
\text { documental }\end{array}$ & Didáctico & Prensa \\
\hline De fijo & 332 & 63 & $61,11 \%$ & $16,16 \%$ & $4,04 \%$ & \\
\hline De fijo que & 55 & 27 & $58,53 \%$ & $32,92 \%$ & & \\
\hline A punto fixo/fijo & 284 & 69 & $39,77 \%$ & $25,49 \%$ & $13,44 \%$ & \\
\hline Ser fixo/fijo que & 16 & 6 & $36,36 \%$ & & $50 \%$ & \\
\hline Fijo que & 24 & 17 & $46,34 \%$ & & & $14,63 \%$ \\
\hline A la fija & & 35 & $88,57 \%$ & & & \\
\hline Ir a la fija & & 13 & $30,76 \%$ & & & $53,84 \%$ \\
\hline En fija (que) & & 5 & $80 \%$ & & & $20 \%$ \\
\hline En fijo (que) & 1 & 1 & $100 \%$ & & & \\
\hline De fija (que) & & 8 & $25 \%$ & & & $25 \%$ \\
\hline Por fixo/fijo & 6 & 4 & & $50 \%$ & & \\
\hline Es fixo/fijo & 3 & 5 & & & & \\
\hline Ésa es la fija & 23 & 3 & $50 \%$ & $46,15 \%$ & & \\
\hline Ésta es la fija & 3 & & $100 \%$ & & & \\
\hline
\end{tabular}

La Tabla II muestra que las variantes de fijo se emplean en español peninsular y en español de América (algunas también manifiestan usos en Filipinas, pero no se han reflejado en la tabla anterior por ser poco numerosos), y que aparecen en textos mayoritariamente escritos (algunas registran ocurrencias orales, como se explicitará en el análisis) procedentes de diferentes géneros textuales, aunque los más frecuentes son los expuestos en esta tabla (hay, en menor medida, presencia de formas en textos líricos, dramáticos, orales, científico-técnicos, etc.).

Con la finalidad de presentar adecuadamente los resultados del análisis, y teniendo en cuenta los datos presentados, la exposición queda dividida en tres secciones: una dedicada a las formas epistémicas de uso extendido y general (de fijo, de fijo que, a punto fixo/fijo, ser fixolfijo que y fijo que); otra en la que se abordan las variantes exclusivamente dialectales (a la fija, ir [alguien] a la fija, en fija [que], en fijo [que] y de fija [que]); y una última en la que se estudian las formas de escaso uso o que, como se ha comprobado en el análisis, están más marcadas por el registro (por fixolfijo, es fixolfijo y ésa/ésta es la fija). 


\subsection{Variantes de uso general y no marcado}

\subsubsection{De fijo}

La forma de fijo, a la que Gaspar y Roig (1853) otorgaba el valor de 'con seguridad', aparece 396 veces con valor epistémico en el corpus (356 en CORDE, 18 en CREA y 22 en CORPES), convirtiéndose en la variante léxica de fijo más recurrente. Es empleada sobre todo en español peninsular (332 ejemplos), aunque también en español de América (63 ocurrencias) y Filipinas (1 aparición). Puede desempeñar la función de locución adverbial (183 casos) y de marcador discursivo (213 ejemplos), función en la que suele ir rodeada por pausas. La época de más frecuencia de uso de esta variante se sitúa entre 1850 y 1900, pero ha sido empleada con regularidad desde 1770 y hasta 2011, por lo que se puede afirmar que es, de todas las analizadas, la que tiene más éxito.

El primer uso con valor epistémico es de 1600 y de fijo actúa como locución adverbial:

(8) - ¡Por l'Alata wa-al-'Uza i por la ídola mayor!, ke si lo ubiera otro kativado sino 'Ali, yo lo abría denegado de fijo (CORDE. Anónimo. [a 1600] 1975. Libro de las batallas. Madrid, España: Gredos, 118).

En (8) el sujeto muestra su actitud firme y segura ante la afirmación presente en la estructura condicional: en esa situación hipotética, él "lo abría denegado" con seguridad.

Con esta función oracional, la estructura aparece de manera recurrente en contextos marcadamente epistémicos que son los que permiten que, con el tiempo, la estructura adquiera ese valor y lo muestre en contextos en los que de fijo es la única marca de la actitud del hablante ante su mensaje. En concreto, es muy habitual con verbos de conocimiento como saber o conocer (supone un 38,25\% del total) y con elementos de polaridad negativa (27,32\%); en estos dos contextos, de fijo actúa de manera semejante a la variante a punto fijo, pero se diferencian por la elevada frecuencia de de fijo en corpus actuales, frente a lo que sucede con $a$ punto fijo, que parece estar dejando de utilizarse. Además, aparece también de manera recurrente en contextos de futuridad $(25,13 \%)$, en estructuras condicionales $(18,03 \%)$, acompañando como refuerzo a subordinadas concesivas y causales $(14,75 \%)$ y en intercambios dialógicos $(12,56 \%)$.

(9) - ¿¿De verdad crees que Saliquet era masón? -le preguntó escéptico su hijo, el capitán Sánchez Bravo.

-No lo sé de fijo. Creo que sí... Antes de la guerra los había en todas partes (CORDE. Gironella, José M. [1986] 1987. Los hombres lloran solos. Barcelona, España: Planeta, 250). 
(10) Oliveira Martins no me ha enviado su nuevo libro o a lo menos no le he recibido. ¿De qué trata? Si es como Los hijos de Don Juan I, será de fijo cosa buena (CORDE. Menéndez Pelayo, Marcelino. [1894] 1946. Carta de 6 de febrero de 1894 [Epistolario de Valera y Menéndez y Pelayo]. Madrid, España: Espasa-Calpe, 485).

(11) Y el artista, riente como niño que olvida sus miedos, aprobó:

-Está tal vez en las azucenas...

-Está de fijo en las azucenas -confirmó Minia-. Todo lo demás es bien deleznable (CORDE. Pardo Bazán, Emilia. [1905] 1991. La Quimera. Madrid, España: Cátedra, 523).

De (9) a (11) se muestran algunos contextos epistémicos frecuentes que han terminado por consolidar el valor de de fijo: en (9) se encuentra con el verbo de conocimiento saber, con un elemento de polaridad negativa y en un contexto dialógico, y de fijo sirve para marcar esa actitud firme del hablante ante el desconocimiento de la información que se pregunta; en (10) aparece en la apódosis de una estructura condicional con el verbo en futuro para marcar el compromiso epistémico del hablante en contextos de duda o probabilidad; finalmente, en (11) se presenta en un diálogo con estructuras paralelas en las que los interlocutores muestran una actitud diferente ante lo dicho, puesto que el primero señala sus dudas (con "tal vez") con respecto al lugar que ocupa una persona y el segundo afirma de manera rotunda y segura que se encuentra "de fijo" en ese lugar.

Su posición es mayoritariamente, como se puede comprobar en los ejemplos de (9) a (11), la que sigue de forma inmediata al verbo $(56,28 \%)$ o la final de la frase $(19,12 \%)$, frente a los ejemplos en los que se presenta de manera antepuesta o inicial $(24,59 \%)$. Aparece siempre en textos escritos, de género narrativo $(48,63 \%)$, documentales e históricos $(20,76 \%)$ y didácticos $(8,74 \%)$ principalmente. Con de fijo la fuente de la información es sobre todo indirecta $(65,57 \%)$, realizada ante todo por conjeturas $(53,55 \%)$, pero también son abundantes los casos de evidencia sensorial o directa $(34,42 \%)$, que coinciden casi totalmente con la coaparición del verbo saber:

(12) Ya le he suplicado a algunos personajes muy serios del país, que si saben alguna canción se la canten al Dr. Schuchard; y no dudo lo hagan hasta sin tiple y tambora; pero si la prensa coge este asunto por su cuenta, de fijo haremos del profesor de Graz el hombre más feliz de la tierra (CORDE. Rodríguez Demorizi, Emilio. [1883-1954] 1975. La palabra folklore en Santo Domingo. Santo Domingo, República Dominicana: Universidad Católica).

(13) El prólogo está firmado por D. Luis de Usoz y Río. colección de reparos gramaticales al Comentario de D. Diego Clemencín. En ciento y quince pasajes nada menos quiere salvar Calderón el texto de Cervantes de las malas inteligencias de 
su comentador, y es lo bueno que casi siempre acierta, porque en el voluminoso y meritorio comentario de Clemencín, es de fijo la parte gramatical la más ligera y endeble (CORDE. Menéndez Pelayo, Marcelino. [1880-81] 1946-48. Historia de los heterodoxos españoles. Madrid, España: CSIC).

En (12) el hablante expresa su compromiso fuerte con una afirmación orientada al futuro en la que la fuente de la información es indirecta y por conjeturas (estructura condicional) y en (13) el hablante está mostrando su seguridad sobre una afirmación que procede de su propia experiencia, puesto que él ha leído el prólogo y puede emitir ese juicio. En general, con la locución de fijo el hablante orienta su compromiso epistémico con lo dicho hacia el presente $(45,35 \%)$, el pasado $(27,86 \%)$ y el futuro $(26,77 \%)$. Por su parte, cuando de fijo funciona como marcador discursivo, suele aparecer rodeado de pausas, como en (14), la primera ocurrencia con valor epistémico:

(14) Si correr cada dia es de tu agrado / De María á Isabel, de Juana á Menga, / Te clavarán, de fijo, hoy ó mañana / Isabel ó María, ó Menga ó Juana (CORDE. Bretón de los Herreros, Manuel. [1828-70] 1884. Poesías. Madrid, España: Imprenta Miguel Ginesta, 413).

En este nivel extraoracional, de fijo ocupa posiciones variables, aunque se observa una preferencia por la anteposición al verbo $(70,89 \%)$ y el inicio de frase $(41,78 \%)$. Siempre se da en textos escritos, siendo el género narrativo $(71,36 \%)$ y el histórico-documental (12,2\%) los más destacados. En relación con los contextos de aparición más habituales, destacan la condicionalidad $(35,21 \%)$, la futuridad $(32,39 \%)$, la polaridad negativa $(20,18 \%)$, los intercambios dialógicos $(15,49 \%)$ y las oraciones subordinadas causales y concesivas $(14,08 \%)$.

(15) La conciencia le venía repitiendo que si se llegaba á descubrir el cuerpo de Gonzalo San Vicente la justicia caería, de fijo, sobre Pedro, creyéndole el matador de su hermano y de Beatriz (CORDE. Larreta, Enrique. 1908. La gloria de don Ramiro. Una vida en tiempos de Felipe Segundo. Madrid, España: Victoriano Suárez, 364).

(16) No quiero que me vean. Ahora no. La niña diría lo de la peseta; y ese Roque es altivo, creo. No querrá limosnas, de fijo. Además, le he visto mirarme con malos ojos (CORDE. Clarín (Leopoldo Alas). [1895] 1981. Teresa. Madrid, España: Castalia, 76).

(17) No te cuento las cosas que se me ocurren en las horas negras de insomnio, porque, de fijo, mis disparates y atrevimientos te parecerían los más estrafalarios que habrías oído en tu vida (CORDE. Pérez Galdós, Benito. [1888-89] 2003. La incógnita. Alicante, España: Universidad de Alicante, 51). 
Los ejemplos de (15) a (17) sirven para mostrar esos contextos epistémicos con los que suele aparecer de manera recurrente el marcador discursivo de fijo: en (15) aparece inserto en una construcción condicional y en (16) junto a un verbo en futuro y con el adverbio negativo; en ambos casos, de fijo muestra el compromiso del hablante con la seguridad de lo dicho en esos contextos hipotéticos; por último, en (17) el marcador discursivo está en una oración subordinada causal y sirve para reforzar la argumentación que ya introduce la conjunción porque. A diferencia de las ocurrencias en las que funciona como locución adverbial, cuando actúa como marcador del discurso presenta evidencias indirectas principalmente por conjetura $(76,05 \%)$, como puede comprobarse en los ejemplos ya mostrados (15) y (16); la fuente de la información es mayoritariamente personal, la perspectiva desde la que se presenta el evento es la tercera persona y orienta las frases modalizadas sobre todo al pasado $(42,25 \%)$.

\subsubsection{De fijo que}

Según Briz, Pons y Portolés (2008), la locución conjuntiva de fijo que 'aumenta el grado de certeza o veracidad que el hablante otorga a lo dicho' y Santos Río (2003, p. 392) la registra como variante de de fijo. En el corpus figuran 82 ocurrencias de esta variante (79 en CORDE, 1 en CREA y 2 en CORPES) y su uso se da en el español en toda su extensión: 55 ejemplos se localizan en el español peninsular y los 27 restantes en el español de América (15 en Perú, 6 en México y ejemplos aislados en otros países).

El primer ejemplo en el que de fijo que posee valor epistémico data de 1863; de acuerdo con los datos del corpus, la mayoría de los ejemplos se localizan en el último cuarto del siglo XIX, por lo que esta información revela que parece ser una variante formal que está desapareciendo en el uso5:

(18) Yo podría, pues, reanudar estas amistades interrumpidas por mis vicisitudes, y salir de apuros para siempre... Más ¿qué diría de mí la sociedad? De fijo que me vendia por una posición; que era poco delicado... ¡Oh, no, no me caso! (CORDE. Pereda, José María de. [1863] 1881. Las bellas teorías [Esbozos y rasguños]. Madrid, España: Imprenta de M. Tello, 25).

Como se puede observar en (18), la opinión del hablante es que "con total seguridad" la sociedad opinaría eso de él. La inserción del que, como sucede con otras variantes de fijo, implica que el hablante delega su responsabilidad sobre lo dicho en otra persona y que el vínculo con esa persona en la que se delega es natural y surge en el acto de habla gracias a la mediación de ese que con el que se intro-

${ }^{5}$ De hecho, una búsqueda rápida en otro corpus actual, el CDE, reporta apenas 35 ocurrencias. 
duce a otro conceptualizador de la escena representada (Delbecque, 2009, p. 637). En realidad, el hablante emplea esta variante para apartarse de manera premeditada de un enunciado que puede resultar fuerte por su valor pragmático, puesto que con de fijo el hablante muestra un fuerte compromiso con la veracidad de lo dicho, y la inserción premeditada del que le permite crear un efecto de atenuación de su propia responsabilidad, de manera que el otro conceptualizador, el nuevo sujeto sintáctico que introduce, sería el responsable de la certeza de las palabras emitidas. De hecho, su posición sintáctica en el enunciado, siempre en posiciones iniciales (ya sea absoluta o anterior al verbo), apoya este efecto pragmático:

(19) De seguro que Moratín nos habría aturdido con sus comedias y Meléndez con su pastoril caramillo, y Gallego con su retumbante trompa. De fijo que Quintana y Sánchez Barbero y Burgos y Lista y Tapia y Martínez de la Rosa habrían lanzado sobre la afligida nación un diluvio de obras poéticas de diversos géneros (CORDE. Pérez Galdós, Benito. [1875] 2002. Memorias de un cortesano de 1815. Alicante, España: Biblioteca Virtual Miguel de Cervantes, Universidad de Alicante, 44).

Así, en (19) la seguridad que el texto transmite en la conjetura que se realiza parece recaer en alguien externo en quien el hablante delega su responsabilidad. En lo referente a los contextos de aparición de esta variante, se registra preferentemente en textos escritos narrativos $(58,53 \%)$ e histórico-documentales $(32,92 \%)$; asimismo, se da principalmente en contextos que inciden en el valor epistémico de la unidad: condicionalidad (43,9\%), diálogos (26,82\%), negación $(23,17 \%)$ y futuridad $(23,17 \%)$ son los más recurrentes, como se puede comprobar en $(20)$, (21) y (22):

20) Creía a pie juntillas que las vacas blancas daban la leche y las negras el café, y si le hubieran dicho que los burros volaban, de fijo que lo hubiera creído (CORDE. Anónimo. a 1911. El recreo de mis hijos. Madrid, España: Saturnino Calleja, 96).

(21) Yo no he hecho nada en mi vida, que merezca esa pena; pero de fijo que me matarán ellos por no haber cumplido mi juramento (CORDE. Zugasti y Sáenz, Julián. [1876-80] 1983. El Bandolerismo. Estudio social y memorias históricas. Córdoba, España: Ediciones Albolafia, Excma. Diputación Provincial de Córdoba).

(22) -Señores, mañana les va a sorprender a ustedes algo que leerán en el periódico, algo de que se hablará pronto en toda España.

- De fijo que éste nos quiere tomar el pelo -dijo Miranda (CORDE. Ganivet, Ángel. [1898] 1983. Los trabajos del infatigable creador Pío Cid. Madrid, España: Cátedra, 276).

En el caso de (20) la locución de fijo que aparece al principio de la apódosis de 
una construcción condicional imposible. En (21) la marca está presente en una oración con el verbo en futuro imperfecto. Por último, en (22) se emplea en un contexto de interacción discursiva que permite incluir al interlocutor en el compromiso con lo dicho (Cornillie, 2016, p. 15), apuntando, entonces, a valores más intersubjetivos.

En consonancia con lo comentado a propósito de esta marca, de fijo que se emplea para mostrar un modo indirecto de acceso a la información (por inferencias, razonamientos y conjeturas) y nunca una evidencia directa de tipo sensorial; con esta marca epistémica, la fuente de la información es personal y la afirmación se presenta en tercera persona orientada al pasado, presente o futuro.

\subsubsection{A punto fixolfijo}

La variante a punto fixo ha sido registrada únicamente en el CORDE con 49 ocurrencias que datan entre 1695 y 1827 . Por su parte, su forma moderna, a punto fijo, cuenta con 308 ejemplos como variante epistémica ${ }^{6}$ desde su primera documentación en 1704: 294 ocurrencias en CORDE (56 de ellas escritas como á punto fijo), 10 en CREA y 4 en CORPES. De manera global, son 357 ocurrencias, de las que 351 actúan como locución adverbial (función principal registrada en Domínguez, 1853) y 6 como marcador discursivo. En (23) se muestra la primera ocurrencia epistémica de á punto fixo, donde actúa como locución adverbial, y en (24) el primer ejemplo como marcador discursivo:

(23) $[. .$.$] que no me consta fixamente si en la distincion de los Diezmos se observa la$ practica corriente, ó lo que previene esta ereccion no puedo discurrir á punto fixo si solo advierto las dudas para que inquiriendose si huvo nuevo Breve, y ereccion, y lo que se practica sea mas superior la censura que lo resuelba (CORDE. Tobar, Baltasar de. [1695] 1954. Compendio bulario indico. Sevilla, España: CSIC-Escuela de Estudios Hispanoamericanos de Sevilla).

(24) Por una rara circunstancia, estaba en trato de alguna intimidad con el fraile palaciego un D. N. Leon, persona de las que suelen figurar en el teatro del mundo sin saberse por qué, no averiguándose de ellas, á punto fijo, el orígen de entrada al trato de los negocios, ni su profesion verdadera (CORDE. Alcalá Galiano, Antonio. [1847-49] 1886. Memorias. Madrid, España: Imprenta Rubiños, II, 141).

En cuanto a su distribución geográfica, los datos revelan que no es una variante marcada desde el punto de vista dialectal, sino que su uso es general, aunque se

${ }^{6}$ Fuera de estos casos, únicamente se documentan dos contextos con valor literal, como sucede en el siguiente ejemplo: "la aguja mira y señala a punto fijo, cierto y señalado de la tierra" (CORDE. Escalante de Mendoza, Juan de. 1575. Itinerario de navegación de los mares y tierras occidentales. Madrid, España: Museo Naval, 298). 
emplea mayoritariamente en español peninsular, donde se identifican 284 casos, frente a los 69 de América y los 4 de Filipinas. Además, es una variante utilizada en escritos muy variados, pero se manifiesta sobre todo en textos narrativos $(39,77 \%)$, históricos y documentales $(25,49 \%)$, didácticos $(13,44 \%)$ y científicotécnicos $(10,92 \%)$. Con respecto a su posición en el discurso, casi siempre aparece pospuesta al verbo $(87,39 \%)$ y preferentemente detrás de él pero sin ocupar la posición final de la frase $(78,15 \%)$.

No obstante, el rasgo que caracteriza a punto fijo frente a otras variantes similares es su distribución en el discurso. Su contexto de aparición más frecuente es el de una construcción con un elemento de polaridad negativa y con un verbo de conocimiento (sobre todo saber, pero son frecuentes otros como conocer o averiguar y verbos de lengua como decir). De hecho, esta variante epistémica aparece con elementos de polaridad negativa en un $73,1 \%$ de las ocasiones y con verbos de conocimiento en un 76,47\% (y, en su mayoría, acompañados de la negación), tal y como se puede comprobar en (25), aunque en otros contextos se suman otros elementos que añaden matiz epistémico, como se observa en (26), donde a punto fijo aparece junto a una perífrasis de posibilidad (se combina con perífrasis de posibilidad y obligación en un $13,44 \%)$ :

(25) No sabemos, pues, si batir palmas y cantar victoria o llorar a lágrima viva, porque si bien es cierto que en aquel día terminó para siempre el aborrecido poder de Calomarde, también lo es que nuestro buen amigo D. Benigno padeció un accidente que puso en gran peligro su preciosa existencia. Cómo sucedió esto es cosa que no se sabe a punto fijo (CORDE. Pérez Galdós, Benito. [1879] 2002. Un faccioso más y algunos frailes menos. Alicante, España: Biblioteca virtual Miguel de Cervantes, Universidad de Alicante, 240).

(26) Mónica no pudo saber a punto fijo qué casta de pájaro era el futuro yerno, ni se le antojaba muy buena; pero viendo cuál estaba la hija, no tuvo más que consentir a todo (CORDE. Carrasquilla, Tomás. [1896] 1952. Frutos de mi tierra. Madrid, España: EPESA, 18).

Por último, los datos indican que esta variante se emplea para mostrar evidencias principalmente personales de tipo sensorial (suponen el 62,46\% del total) y, en menor medida, cognitivas por inferencia, razonamiento o conjetura $(37,53 \%)$ que están orientadas al presente $(64,14 \%)$ y al pasado $(31,09 \%)$. La perspectiva desde la que se impone la escena es principalmente la del hablante, esto es, aparece en primera persona $(31,65 \%)$, pero también es muy habitual que se esconda tras construcciones de tipo impersonal $(35,01 \%)$ o se presente el compromiso epistémico de una tercera persona sobre lo dicho $(28,85 \%)$. En (25) se puede comprobar que el hablante esconde su responsabilidad sobre el desconocimiento de cómo tuvo lugar el suceso al presentar la afirmación en una estructura impersonal. En 
(27) se observa el compromiso epistémico del hablante con la falta de conocimiento sobre la afirmación realizada:

(27) Trae también no sé qué embajadas socialistas o misiones diplomáticas cerca de la Segunda o la Tercera Internacional. Aún no lo sé a punto fijo (CORDE. León, Ricardo. 1941. Cristo en los infiernos. Madrid, España: Victoriano Suárez, 202).

\subsubsection{Ser fixolfijo que}

Es fixo que es una variante epistémica que cuenta únicamente con 11 ejemplos extraídos de CORDE fechados entre 1726 y 1740 y registrados en obras didácticas de Benito J. Feijoo, por lo que parece ser una preferencia personal del autor. No obstante, sus contextos de aparición son equivalentes a los de su forma actual es fijo que, de la que se han encontrado también 11 ocurrencias ( 3 en su forma era fijo que) datadas entre 1790 y 2011 (7 procedentes de CORDE, 1 de CREA y 3 de CORPES). Una búsqueda rápida en el CDE revela que esta variante tiene pocas ocurrencias en comparación con fijo que, marca epistémica que, como se verá en el siguiente epígrafe, se emplea en los mismos contextos y usos que ser fijo que (con alguna pequeña ampliación de contextos), pero que, debido a su forma más breve y directa, está siendo más empleada actualmente.

Ser fixolfijo que se emplea en posiciones iniciales (95,45\%) o antepuesta al verbo, en escritos sobre todo didácticos $(50 \%)$ y narrativos $(36,36 \%)$ de español peninsular (16 contextos) y de América (6 ejemplos). Su primera aparición en el corpus es de 1726:

(28) La tercera, que no sea jactancioso en obstentar el poder, y seguridad de su Arte: porque siendo cierto, que no ay tal seguridad en ella, es fixo que el que la propone tal, o es muy ignorante, o muy engañador (CORDE. Feijoo, Benito J. [1726] 1998. Teatro crítico universal, I. Oviedo, España: Instituto Feijoo del siglo XVIII).

En el ejemplo de (28) la marca epistémica es fixo que alerta al lector de que lo dicho es una certeza que él defiende y que el hablante, debido a los principios conversacionales, debería compartir. Esta variante de fijo se emplea para mostrar evidencias obtenidas por procesos cognitivos de conjetura $(59,09 \%)$ e inferencia $(22,72 \%)$ sobre todo, orientadas al pasado $(50 \%)$ y al presente $(45,45 \%)$ y presentadas en tercera persona de manera mayoritaria $(63,63 \%)$. Entre los contextos que refuerzan el valor epistémico destacan las estructuras condicionales $(31,81 \%)$ y la presencia de conjunciones causales y concesivas $(31,81 \%)$ :

(29) Si se enteraba el subprefecto era fijo que lo metía preso a fin de cobrarle carcelaje... (CORDE. Alegría, Ciro. [1941] 1978. El mundo es ancho y ajeno. Caracas, Vene- 
zuela: Biblioteca Ayacucho, 76).

(30) En cambio, yo me pongo el cinturón de seguridad porque es fijo que se trata de un fanfarrón de cantina con botas vaqueras, mangas cortas apretadas que dejan ver los tatuajes y una cicatriz en la mejilla o en el mentón (CORPES. Forch, Juan. 2002. El campeón. Providencia, Santiago de Chile, Chile: Alfaguara).

En (29) se observa era fijo que en la apódosis de una condicional y el hablante muestra su seguridad sobre una conjetura orientada al pasado. Por otro lado, (30) muestra la combinación de es fijo que con la conjunción causal porque, contexto en el que la marca epistémica refuerza el razonamiento del hablante que la propia conjunción introduce.

\subsubsection{Fijo que}

Los datos de corpus obtenidos de la búsqueda de fijo que indican que es una variante en auge en los últimos tiempos y parece ser una evolución por simplificación de ser fijo que o de fijo que. A pesar de que se cuenta únicamente con 41 ejemplos, su distribución temporal demuestra que su uso es actual: hay 5 ejemplos en CORDE (nunca registrado como la que podría ser su variante más antigua, fixo que), 13 en CREA y 23 en CORPES; la mayoría de los ejemplos datan entre 2001 y 2012, siendo escasos los del siglo anterior. Además, aparece principalmente en textos escritos, en español peninsular ( 24 ejemplos) y en español de América (17 casos), pero figuran 4 ocurrencias orales extraídas de blogs y algunos de los ejemplos escritos se dan en contextos que tratan de imitar, en muchas ocasiones, la oralidad (19 ejemplos en textos narrativos, 6 en prensa y otros 6 en blogs, 4 en sociedad y 3 en teatro).

La primera ocurrencia con el valor epistémico de 'con certeza o seguridad' (Salamanca, 1996) es de 1955, y queda reproducida en (31):

(31) Volviendo a lo de antes, me ha quedado un remusgo... No sé. A lo mejor les oí mal, ¿sabe? Fijo que les oí mal... Luego puse mucho cuidado en ver qué hacían todos los días, y era siempre como antes (CORDE. Quiroga, Elena. [1955] 1962. La enferma. Barcelona, España: Noguer, 150).

Al igual que sucedía con es fijo que y con de fijo que, esta marca epistémica es empleada por el hablante únicamente en posiciones antepuestas al verbo, preferentemente iniciando frase $(46,34 \%)$ o en posición inicial absoluta $(39,02 \%)$, para mostrar el compromiso epistémico de una tercera persona $(46,34 \%)$ con la verdad de lo afirmado y, en la mayoría de ocasiones, sirve para reforzar la seguridad en lo dicho en casos en los que el modo de acceso a la información se realiza por conjeturas $(85,36 \%)$ : 
(32) Me dice que le encanta la idea y cómo dibujo. Dice que a ella nunca le han atraído mucho los cómics pero que si viera uno así en una librería, fijo que se lo compraba (CORPES. Muñoz Avia, Rodrigo. 2011. La jaula de los gorilas. Madrid, España: Alfaguara).

En (32) se comprueba este contexto de aparición habitual de fijo que: el hablante muestra la certeza de la afirmación (la acción de comprar un libro) en un contexto conjetural, pues fijo que aparece en la apódosis de una estructura condicional. El contenido de la frase modalizada puede estar orientado al futuro (46,34\%), al pasado (36,58\%) y al presente (17,07\%). De hecho, los contextos de refuerzo epistémico más abundantes de esta forma son la futuridad $(43,9 \%)$ y condicionalidad (17,07\%), en los que fijo que muestra el compromiso epistémico del hablante en un contexto de duda, posibilidad o conjetura; en algunos ejemplos, en los que se acompaña de conjunciones causales y concesivas (17,07\%), fijo que incide en la inferencia realizada por el hablante y en otros contextos va acompañada de seguro o de la repetición de contenidos, otorgando la marca epistémica el valor de refuerzo e intensificación de lo dicho:

(33) ¿Las regalan? Seguro que las regalan. Fijo que las tienen que dar con las tapaderas del yogur, con los comprobantes de compra de los tambores de detergente, con las envueltas del chocolate (CORPES. Burgos, Antonio. 15/3/2006. El voto hipotecado. ABC.es. Madrid, España: abc.es).

En el ejemplo de (33) se observan los dos elementos de refuerzo cognitivo mostrados: por un lado, la reiteración que hace el hablante de la idea presentada ("las regalan", "las tienen que dar con") y, por otro lado, "seguro que" en estructura paralela a la de "fijo que", con la que el hablante consigue esa intensificación en la seguridad de lo dicho.

\subsection{Variantes marcadamente dialectales}

\subsubsection{A la fija}

Según las fuentes consultadas, a la fija se limita a las áreas geográficas de Chile,

\footnotetext{
${ }^{7}$ No se aborda aquí esta misma locución empleada en Argentina con el valor 'con éxito' (Corominas y Pascual, 1980) y que parece haber surgido por extensión de significado: "Deje estar: / que luego hemos de acabar / con toda esa sabandija, / de siguro, y a la fija: / y a ellos se les hace broma, / pero si medio se asoma / Pacheco por la cuchilla, / Frutos Rivera ni ensilla... / y en pelos me lo desloma" (CORDE. Ascasubi, Hilario. 1853. Paulino Lucero. México: Fondo de Cultura Económica, 99-100).
} 
Uruguay (RAE, 1970), Colombia y otros países centroamericanos como Honduras y Nicaragua en los que se registra "casi siempre en el habla popular" (RAE, 2009, pp. 2376-2377). La búsqueda realizada revela que esta delimitación es válida: se documentan 35 ocurrencias ( 29 en CORDE, 3 en CREA y 3 en CORPES) de las que 10 se localizan en Uruguay (7 en el mismo autor y obra), 21 en Argentina (del mismo autor) y 5 en Colombia. Además, la búsqueda en el CDE sigue confirmando estos datos: de los 130 ejemplos, 122 se registran en Colombia, 4 en Nicaragua, 2 en Venezuela, 1 en Costa Rica y 1 en Uruguay.

De acuerdo con el corpus, la primera ocurrencia con valor epistémico es de 1853:

(34) Pues, señor, / partiendo de una alvertencia, / desde el día veintidós, / y rumbiando a las funciones, / fui a golpiarme al Canelón, / con el ñato Salvador, / me pasé todo ese día; / y el liendre con su intención, / sintiéndome algunos riales, / y sabiendo mi afición / a echar un trabajo, a la fija / esa noche me apedó, y orejiando la pasamos (CORDE. Ascasubi, Hilario. 1853. Paulino Lucero. México: Fondo de Cultura Económica, 40-41).

En (34) se interpreta que Salvador le emborrachó "con seguridad", sin duda alguna.

A la fija suele actuar como locución adverbial, como en (34), aunque se han identificado 4 ocurrencias en las que se utiliza como marcador discursivo, como en (35):

(35) Queremos, sí, que nos diga: / cuando tenga que embarcarse / ¿cómo hará para no echarse / enfermo de la barriga? / porque el mareo fatiga / y da como chavalongo; / razón por la cual supongo / que si se embarca, a la fija, / en su primer revoltija / de tripas, larga el mondongo (CORDE. Ascasubi, Hilario. 1872. Aniceto el Gallo. México: Fondo de Cultura Económica, 118).

La posición de esta variante léxica de fijo no aporta datos concluyentes, puesto que aparece en un $45,71 \%$ de las ocasiones en posición antepuesta al verbo y en un $54,28 \%$ en posición pospuesta. Se registra de manera prioritaria $(88,57 \%)$ en obras escritas de género narrativo (novela, épica); solamente figura un caso de oralidad. Resulta interesante comentar que no entra en conflicto con la locución adverbial a punto fijo, pues únicamente aparece registrada en una ocasión en el contexto mayoritario en el que suele aparecer a punto fijo, esto es, con verbos de conocimiento y en entornos negativos (36), y se acerca más a de fijo, ya que se emplea más en contextos futuros $(45,71 \%)$ y condicionales $(14,28 \%)$, como se refleja en los ejemplos (37) y (38): 
(36) -¿Llovía y tronaba en ese momento, don Anacleto?

-No lo sé a la fija; pero el cielo estaba tordillo oscuro, y "refucilaba" fuerte... (CORDE. Acevedo Díaz, Eduardo. 1890. Nativa. Alicante, España: Biblioteca Virtual Miguel de Cervantes, Universidad de Alicante, 70).

(37) Sin duda; porque las cosas / demuestran que este verano, / más que a la fija, paisano, / se lo lleva el diablo a Rosas (CORDE. Ascasubi, Hilario. 1872. Aniceto el Gallo. México: Fondo de Cultura Económica, 250).

(38) Me temo que maquina regresar a los Estados Unidos, donde a la fija caería otra vez en las zarpas de Freddy Prescott (CORPES. Espinosa, Germán. 2004. Cuando besan las sombras. Bogotá, Colombia: Alfaguara).

Del ejemplo (37) destaca que esa actitud cierta que muestra el hablante hacia un hecho futuro viene además reforzada con la estructura comparativa "más que" y con la presencia del marcador conversacional de modalidad epistémica sin $d u d a^{8}$.

Finalmente, al igual que de fijo, la fuente de la información suele ser cognitiva, pues muestra evidencias por conjetura, inferencia o razonamiento (80\%), pero de fijo se centraba mayoritariamente en las evidencias por conjetura y a la fija indica los tres tipos.

\subsubsection{Ir (alguien) a la fija}

La variante ir (alguien) a la fija comenzó a registrarse en el diccionario académico de 2001 como locución verbal propia de las zonas colombiana y nicaragüense y con el significado de 'ir sobre seguro'. En el corpus solamente se documentan 13 ocurrencias de esta forma, 10 registradas en Colombia y 3 en Argentina. Una búsqueda rápida en la versión dialectal del CDE confirmó estos datos: aparecen 117 ejemplos y 96 son del habla propia de Colombia (7 de Estados Unidos, 5 de Perú, 2 de Venezuela, 2 de Guatemala y ejemplos aislados en otras zonas, entre ellas, España, pero en este caso se trata de una opinión en un foro, por lo que se desconoce la procedencia de la persona).

La primera ocurrencia, reproducida en (39), data de 1853 (en la misma obra que a la fija) y se acompaña de un más ponderativo que recalca la actitud epistémica del sujeto:

(39) Entonces, por si lo pillo / y me atropella Balija, / para irme más a la fija / voy a llevar mi cuchillo (CORDE. Ascasubi, Hilario. 1853. Paulino Lucero. México: Fondo de Cultura Económica, 262).

${ }^{8}$ En otros contextos, se acompaña del intensificador tan: "ya que Vuecelencia tiene tan a la fija el costitucionar una República Urquizana” (CORDE. Ascasubi, Hilario. 1872. Aniceto el Gallo. México: Fondo de Cultura Económica, 82). 
Es una variante también propia de textos escritos y, según el corpus, se presenta en textos de prensa $(53,84 \%)$, narrativa $(30,76 \%)$, sociedad y teatro. Por su funcionamiento, se desmarca completamente del resto de variantes, puesto que, además de su marcado carácter dialectal, no se ha registrado otra locución verbal que tenga como base la forma fijo. El hablante la emplea orientada sobre todo al presente $(53,84 \%)$ para mostrar evidencias de las que él es la fuente informativa y en las que el acceso a la información se hace ante todo por experiencias sensoriales compartidas con otros hablantes:

(40) Para ir a la fija, señores, siempre tengan en su ropero unos buenos jeans y varias camisas (CORPES. Arango Sepúlveda, Beatriz. 1/12/2007. Ideas de qué me pongo para todos. El Colombiano.com. Medellín, Colombia: elcolombiano.com.co).

Así, lo que transmite (40) es algo que todo el mundo sabe: con un vaquero y varias camisas se logra un buen fondo de armario y 'se va sobre seguro'.

$\mathrm{El}$ análisis de los contextos de aparición apenas reporta datos: en una ocasión aparece en construcción condicional, pero, a diferencia del resto, en la prótasis (41); en dos casos aparece con el verbo en futuro (42); en un caso se combina con otra locución epistémica y en otro refuerza el razonamiento marcado por pues:

(41) Si de ir a la fija se trata, basta con recurrir a estos cuatro expertos para que su matrimonio no pase inadvertido ni mucho menos sea uno del montón (CORPES. 10/2010. Con los que saben. Revista Fucsia.com. Santa Fe de Bogotá, Colombia: revistafucsia.com).

(42) De pantalón y saco negro, con un toque de color en la camisa, irá a la fija a su oficina o a una cita de negocios (CORPES. 10/1/2012. Se puede estar a la moda a punta de prendas básicas. El Tiempo.com. Bogotá, Colombia: eltiempo.com).

Esta independencia de contextos de rutinización de carácter epistémico se debe, claramente, a que la variante ir (alguien) a la fija ha sido creada con ese significado desde su origen y no es posible confundirla con otras variantes homónimas?

\subsubsection{En fija (que)}

En fija es una variante empleada en Argentina y Uruguay (RAE, 1970). Es poco abundante en el corpus: solamente constan 4 ocurrencias, todas localizadas en

\footnotetext{
${ }^{9}$ Resulta interesante comentar que en la búsqueda de corpus se ha descubierto un caso de venir (alguien) a la fija, que parece poseer el mismo significado: "Vuelven locos de contentos / cuando han venido a la fija; / antes que ninguno elija / empiezan con todo empeño, / como dijo un santiagueño, / a hacerse la repartija" (CORDE. Hernández, José. 1879. La vuelta de Martín Fierro. Madrid, España: Castalia).
} 
CORDE en novelas de un autor uruguayo. La búsqueda en el CDE reporta 10 ejemplos con el valor epistémico de 'con seguridad', 5 en Uruguay y 5 en Argentina. En los 4 ejemplos de CORDE actúa como locución adverbial; así sucede en (43):

(43) -La jugada va’ ser machasa, les vamos a juntar las cabesas. Lástima que haiga poca plata del lau contrario.

-No crea, a los de la estansia les gusta en fija -observó Madeja, el compositor (CORDE. Reyles, Carlos. [1932] 1969. El gaucho Florido. La novela de la estancia cimarrona y del gaucho crudo. Madrid, España: Espasa-Calpe, 38).

En las cuatro ocurrencias aparece pospuesto al verbo y son intervenciones que imitan la lengua oral; además, aunque en (43) la orientación es presente, en el resto se orienta al pasado y muestra la seguridad del hablante sobre un hecho certero que está narrando porque deriva de una experiencia sensorial directa que le sucedió a él, como en (44):

(44) -Un día la aguaité en el lavadero, escondido entre los sauses. Cuando la atropellé en fija, ¿quedrás creer que sacó de entre las piedras la cuchilla de cuerear y se me vino al humo? (CORDE. Reyles, Carlos. [1932] 1969. El gaucho Florido. La novela de la estancia cimarrona y del gaucho crudo. Madrid, España: Espasa-Calpe).

Por último, en los ejemplos del CDE se ha descubierto la locución conjuntiva en fija que con el mismo valor que en fija; se puede comprobar en (45):

(45) - ¡No! Estaba en la fiesta bebiendo y cantando a dúo con una de las chicas, a la que después llevó en su auto.

-¿Qué tiene de malo? En fija que cantaban alguna canción de Viglietti, un villancico navideño, o el Mesías de Haendel o la Despedida de los Asaltantes (CDE. 2013. ¡Tanto escándalo por una fiestita inocente! Diario La República).

\subsubsection{En fijo (que)}

Sobre en fijo la RAE (2009, p. 2377) señala que es una locución adverbial que se utilizaba "antiguamente" tanto en el español de América como en el europeo. El diccionario académico de 2001 indica que es una variante léxica empleada en Argentina y de uso rural. La realidad es que no se cuenta con datos suficientes para corroborar estas afirmaciones: tras una búsqueda en los corpus de la RAE y en la versión dialectal del $\mathrm{CDE}$, solo se han descubierto dos casos como marca epistémica, uno como locución adverbial, que se refleja en (46), y otro como locución conjuntiva, presentado en (47): 
(46) Las de Ferraz propusieron el expediente a las de Silva, que sin consultarlo con el papá, con quien no consultaban nada, aceptaron locas de alegría. No podrían lucirse tanto de telón adentro; pero se divertirían en fijo; verían cosas muy agradables, muy nuevas, y hasta podrían coquetear con los cantantes (CORDE. Clarín (Leopoldo Alas). [1891] 1990. Su único hijo. Madrid, España: Cátedra, 408).

(47) Miseria pensó que el mesmito Infierno se había mudao a su casa, y llegó, mirando como pato el arriador, a esa pueblada de diablos. "Si escapo d'ésta -se dijo- en fijo que ya nunca la pierdo” (CORDE. Güiraldes, Ricardo. [1926] 1983. Don Segundo Sombra. Madrid, España: Ayacucho, 267-268).

Estas dos formas aparecen en el género narrativo, pero mientras que la forma en fijo se registra en el español peninsular, la locución conjuntiva aparece en un texto de autor argentino. Las dos orientan la actitud segura del hablante hacia un hecho futuro en contextos marcadamente epistémicos por su condicionalidad: en (46) la locución adverbial aparece con el verbo en condicional y en construcción adversativa; en (47) la locución conjuntiva aparece en la apódosis de una construcción condicional y en un contexto dialógico materializado en un monólogo interior del protagonista. En los dos casos la fuente de la información es personal y se accede a ella de manera cognitiva.

\subsubsection{De fija (que)}

La locución adverbial de fija es una variante propia del Río de la Plata (RAE, 2009, p. 2377), pero los corpus de la RAE no reportan ocurrencias de de fija como marca epistémica. Solamente se dispone del ejemplo ofrecido por la RAE, copiado en (48):

(48) De fija se va a morir sufriendo como un perro (Página 12/4/2004).

La versión dialectal del CDE muestra 3 casos de la locución adverbial de fija como marca epistémica, uno de Paraguay, otro de Estados Unidos y otro de Argentina, y están datados entre 2011 y 2013. De estas 4 ocurrencias totales, 2 aparecen en contextos escritos de prensa y 2 en contextos orales de blogs. Los contextos de aparición sí que son relevantes puesto que en los cuatro casos el hablante la emplea para presentar una actitud firme y segura orientada hacia un hecho futuro. En tres casos va acompañada de un verbo en futuro y en dos ejemplos se presenta en una condicional:

(49) Si te teñís el pelo de naranjado ella aparecerá a el día siguiente con senda cabeza de zanahoria; te copiará todo tu ropero y si lo que te ponés no lo encuentra en plaza, de fija te lo pedirá prestado para sacar el modelo con su modista... (CDE. 
2011. Flor de Camalote. Paraguay. Disponible en http://flordecamalote.blogspot. com/2011/06/amistades-peligrosas.html).

Su posición siempre es antepuesta al verbo y la fuente de la información siempre es personal, pues el hablante realiza una conjetura sobre un suceso venidero.

La búsqueda de de fija en los corpus de la Academia permitió descubrir una variante léxica no documentada en obras lexicográficas, la locución conjuntiva de fija que, de la que se cuenta con un ejemplo en Argentina, reproducido en (50):

(50) Vos fíjate, mamá, el pibe está débil y capaz que le hace impresión si uno le cuenta. Los enfermos como él se imaginan cada cosa, de fija que va a creer que estoy afilando con Laura. Mejor que no sepa que vamos a Gimnasia (CREA. Cortázar, Julio. 1983. Reunión y otros relatos. Barcelona, España: Seix Barral, 38).

El CDE aportó 3 ocurrencias más, una en Argentina en 1959 (también de Cortázar), otra en Bolivia en 2008 y la última en Uruguay en 2011. Los dos ejemplos de Argentina son del género relato y los dos restantes de blogs (variedad oral). Del mismo modo que de fija, la locución conjuntiva aparece en posición inicial de frase y con ella el hablante muestra evidencias personales a las que accede de manera indirecta o cognitiva, por inferencia o conjeturas, y 3 de las ocurrencias están orientadas hacia el futuro, frente a una orientada al presente. Los contextos de aparición son epistémicos: en tres casos acompaña a "ir a + infinitivo", como en (50). Se comporta, por tanto, como de fija.

La conclusión a la que se llega es que de fija (que) es una variante empleada de manera reciente y muy esporádica, por lo que habrá que esperar unos años para observar qué sucede finalmente con esta locución en la evolución de la lengua.

\subsection{Datos relevantes sobre otras variantes de escaso uso o marcadas por el registro}

\subsubsection{Por fixo/fijo}

Por fijo no aparece registrada en las obras lexicográficas consultadas. No obstante, en CORDE aparecen 10 ejemplos ( 5 escritos en su forma antigua por fixo): 6 en España, 2 en Chile y 2 en Venezuela. Por su escasa presencia (el CDE apenas reporta dos casos con el valor 'por seguro'), se puede afirmar que no puede competir en la expresión de la epistemicidad con las otras variantes y que es una forma que no ha tenido éxito. El primer contexto con el valor epistémico de 'sin duda, con total seguridad' es el de (51): 
(51) Mediodía era por fijo, / Las doce daba el reló; / Comiendo está con los grandes / El rey Alfonso en Leon (CORDE. Anónimo. [1600-04] 1851. Romances, en Romancero general. Madrid, España: Rivadeneira, I, 553).

En la mayoría de los ejemplos actúa como una locución adverbial con la que el hablante expresa su compromiso epistémico con la seguridad de lo dicho; así, en (52) se entiende que cualquiera tendrá 'por seguro' que la respuesta fue "maligna chanza":

(52) Y a una amiga de su íntima confianza / Que allí se hallaba, con misterio dijo: / "Lástima es que ese joven de esperanza / No sea de ascendientes nobles hijo.” / Que la respuesta fue maligna chanza, / Esto cualquiera lo tendrá por fijo, / Y con sorpresa tal llena de susto, / Hizo Leonor un jesto de disgusto (CORDE. Sanfuentes, Salvador. [1842] 1846. El campanario. Valparaíso, Chile: Imprenta del Mercurio, 747).

Su posición siempre es pospuesta al verbo y nunca parentética. Los diez ejemplos se documentan en textos escritos, sobre todo histórico-documentales (50\%) y líricos (20\%). La ausencia de datos impide realizar una estimación clara de su empleo, pero es posible señalar que se orienta al presente y al pasado; además, en relación con los contextos epistémicos, solo se combina en dos casos con el futuro, en una ocurrencia con una perífrasis de obligación y en otra con desde luego; finalmente, por fijo presenta, mayoritariamente, evidencias indirectas del hablante por conjetura o inferencia.

(53) Sentaremos por fijo que Túbal dió principio a la fábrica de la torre, y que Hércules el famoso la reedificó y amplió (CORDE. Menéndez Pelayo, Marcelino. [1880-81] 1946-48. Historia de los heterodoxos españoles. Madrid, España: CSIC, II, 410).

En (53) se puede comprobar la aparición de la locución por fijo en un contexto de futuridad; en este fragmento, el hablante está mostrando su seguridad en lo dicho realizando una afirmación basada en conjeturas personales.

\subsubsection{Es fixo/fijo}

La combinación del verbo copulativo ser y de fijo con el significado de 'cierto, seguro' es abundante en el corpus, pero su fijación en la forma conjunta es fijo como marca epistémica tiene poca presencia (igualmente sucede en CDE). Concretamente, se dispone de 9 ejemplos (uno en su forma antigua es fixo): 5 de español de América, 3 de España y 1 de Filipinas, de los que 8 funcionan como marcador discursivo en entornos parentéticos, como se puede observar en su ocurrencia más antigua: 
(54) MENTOR: A veces no basta el brío; / con poderosos contrarios, / huir es vencer. TELÉMACO: Es fijo; / pero no son poderosos, / que yo en mi bien lo examino (CORDE. Vela, Eusebio. [p 1713] 2003. Comedia nueva de Si el amor excede al arte, ni amor ni arte a la prudencia. Alicante, España: Biblioteca Virtual Miguel de Cervantes, Universidad de Alicante).

El ejemplo (54) muestra el entorno más característico de esta marca: entre pausas, con posición algo más libre (en un $77,77 \%$ antepuesto al verbo y en un $22,22 \%$ al final) y en textos escritos de variado género. Presenta, ante todo, evidencias personales indirectas $(66,66 \%)$ y alguna directa sensorial $(33,33 \%)$ que el hablante orienta sobre todo al presente $(88,88 \%)$ en contextos dialógicos $(55,55 \%)$ como el anteriormente presentado; además, en un par de contextos se descubren otros elementos con los que el sujeto apela a la certeza de lo afirmado, como sucede en (55) con es cierto en estructura paralela:

(55) En quanto á la tropa Pampanga no sé qué motivo pueda haver tenido para su buelta, si son los faroles que dicen; creo que bean estrellas á medio día, no viéndolas nosotros á media noche; que ay muchos traidores es cierto: que se han dado las tumores precauciones contra ellos, es fixo; luego no es ese el motivo (CORDE. Braña, Miguel. [1763] 1908. Carta del P. Braña al Sr. Anda. Madrid, España: Imprenta del Asilo de Huérfanos, 254).

\subsection{3. Ésa/Ésta es la fija}

El análisis de las variantes de fijo finaliza con las expresiones invariables ésa es la fija y ésta es la fija, documentadas por primera vez en el diccionario usual de la RAE de 1925, la primera marcada para registros familiares (y en RAE, 2014 con uso coloquial) con el significado 'con que se aprueba como cierta alguna cosa' y la segunda con el valor 'que indica haber llegado ya la ocasión de que ocurra aquello que se teme o se espera'. De acuerdo con el significado señalado, esa es la fija tendría un uso epistémico, puesto que el hablante la emplea para aprobar una afirmación como cierta, y debería aparecer ante todo en contextos dialógicos. Por su parte, esta es la fija también codifica valores subjetivos, pero su uso difiere de la anterior y el hablante la utilizará para confirmar una propuesta o suposición que formaba parte de sus expectativas personales.

Se han localizado 26 ocurrencias de esa es la fija, todas en CORDE, 3 en español de América (en Cuba y Uruguay) y el resto en español peninsular, en textos escritos narrativos $(50 \%)$, histórico-documentales $(46,15 \%)$ y dramáticos $(3,84 \%)$ fechados entre 1876 y 1972 . Esta expresión siempre aparece entre pausas y en contextos dialógicos; además, es significativa su presencia en frases exclamativas $(30,76 \%)$ : 
(56) - ¿Quiere decirse, Carpio, que ese voto es otro compromiso para el probe? -Como too lo que se nos da, Gorio... que más vicio que esta soflamería es el refrán que sabemos: “¿aónde irá el güey que no are?”

-Esa es la fija, Carpio... Y voy a decirte un sentir (CORDE. Pereda, José María de. [1879] 2003. Don Gonzalo González de la Gonzalera. Alicante, España: Universidad de Alicante).

(57) -Usted lo ha dicho, respondió José; conviene saber nadar y guardar la ropa, y por eso ahora debemos pensar en salir a la orilla, dejándose de pequeñeces y emprendiendo negocios gordos.

-¡Esa es la fija! exclamó Francisco (CORDE. Zugasti y Sáenz, Julián. [1876-80] 1983. El Bandolerismo. Córdoba, España: Ediciones Albolafia).

En (56) y (57) esa es la fija se inserta en contextos dialógicos y el hablante la emplea para mostrar su compromiso epistémico con una opinión introducida por su interlocutor. El corpus revela que la evidencia presentada por esta expresión es sobre todo indirecta, basada en razonamientos y conjeturas, y se utiliza principalmente orientada al presente y al futuro. Por otra parte, el contenido modal epistémico que transmite queda patente en ejemplos como (58), donde, en un intercambio conversacional, los interlocutores encadenan dos variantes de fijo para expresar su compromiso con lo afirmado ${ }^{10}$ :

(58) -Se abrieron varios y, por lo tanto, no sé qué decirte; pero ese baúl ¿qué contenía? -Algún dinero en oro.

-Pues entonces, de fijo que no se abrió.

- ¿No es verdad, muchachos?

-Esa es la fija, respondieron a una los bandidos (CORDE. Zugasti y Sáenz, Julián. [1876-80] 1983. El Bandolerismo. Estudio social y memorias históricas. Córdoba, España: Ediciones Albolafia, III, 121).

En cuanto a esta es la fija, su empleo es escaso. En el corpus únicamente se registran tres ejemplos, extraídos de CORDE, en novelas de español peninsular fechadas en 1889, 1911 y 1941; el CDE no reporta datos de esta expresión. En los tres ejemplos, aparece entre pausas y expresa conjeturas personales orientadas al futuro y en contextos en los que el hablante se dirige directamente a su interlocutor, como se comprueba en (59):

(59) Hoy, más que digas por tema lo que te dé la gana, me quieres, me requieres, estás

${ }^{10}$ En el corpus se ha descubierto algún caso de la estructura es la fija, que parece ser una variante de esa es la fija con el valor 'lo que acabo de mencionar es la verdad': “-¡Vaya un soldado de ñoña! Militar, y no tañer la vihuela, cuénteselo usted a su abuela, dice el refrán, y es la fija” (CORDE. Zugasti y Sáenz, Julián. [1876-80] 1983. El Bandolerismo. Córdoba, España: Ediciones Albolafia, I, 139). 
enamoraa de mí... Poquito a poco te ha ido entrando... y así que yo te falte, se te va a acabar el mundo. Esta es la fija... Ya lo verás, ya lo verás (CORDE. Pardo Bazán, Emilia. [1889] 2002. Insolación. Alicante, España: Biblioteca Virtual Miguel de Cervantes, Universidad de Alicante).

En (59) el hablante expresa que por fin ha llegado el momento de que algo que esperaba tenga lugar, por lo que sus expectativas se acaban convirtiendo en certezas.

\section{CONCLUSIONES}

El análisis de las variantes léxicas de fijo con valor epistémico en español demuestra que estas formas se han especializado en la expresión de este contenido y de la evidencialidad debido a un proceso de subjetivación que les ha afectado en su evolución, mostrando la importancia que este procedimiento tiene en la gramaticalización de unidades lingüísticas. Aunque se cuenta con formas similares para la expresión de estos valores, la realidad es que toda distinción en la forma conlleva una diferencia en el significado y las variantes de fijo expresan unos contenidos particulares con unas funciones diferentes, demostrando que el hablante puede configurar los eventos de la realidad desde diferentes perspectivas y para expresar matices diversos.

Del análisis de corpus que se ha realizado, se desprenden aspectos comunes que conviene resaltar. En primer lugar, resulta de interés mostrar de manera unificada cuáles son los contextos más recurrentes que han favorecido el proceso de rutinización de estas unidades epistémicas:

Tabla III. Contextos de aparición frecuentes para las variantes de fijo con más ocurrencias.

\begin{tabular}{|l|r|r|r|r|r|r|}
\cline { 2 - 7 } \multicolumn{1}{c|}{} & $\begin{array}{c}\text { Verbo de } \\
\text { conocimiento }\end{array}$ & Negación & Futuro & Condicional & Diálogo & Subordinada \\
\hline De fijo & $17,67 \%$ & $23,48 \%$ & $29,04 \%$ & $27,27 \%$ & $14,14 \%$ & $14,39 \%$ \\
\hline De fijo que & & $23,17 \%$ & $23,17 \%$ & $43,9 \%$ & $26,82 \%$ & \\
\hline $\begin{array}{l}\text { A punto } \\
\text { fixo/fijo }\end{array}$ & $76,47 \%$ & $73,1 \%$ & & & & \\
\hline $\begin{array}{l}\text { Ser fixo/ } \\
\text { fijo que }\end{array}$ & & & & $31,81 \%$ & & $31,81 \%$ \\
\hline Fijo que & & & $43,9 \%$ & $17,07 \%$ & & $17,07 \%$ \\
\hline
\end{tabular}


Continuación Tabla III.

\begin{tabular}{|l|l|l|r|r|r|l|}
\hline A la fija & & & $45,71 \%$ & $14,28 \%$ & & \\
\hline Ir a la fija & & & $15,48 \%$ & $7,69 \%$ & & \\
\hline Ésa es la fija & & & & & $100 \%$ & \\
\hline
\end{tabular}

La Tabla III, en la que figuran las variantes léxicas de fijo con más de diez ocurrencias en el corpus, refleja que las formas de esta familia léxica presentan contextos de aparición frecuentes, entre los que destacan las estructuras con valor condicional y futuro por el mayor número de marcas epistémicas encontradas en estos contextos; asimismo, los otros contextos recogidos en esta tabla revelan patrones comunes que han favorecido ese proceso de rutinización. En segundo lugar, se puede observar en la Tabla IV la codificación del contenido evidencial que manifiestan las variantes de fijo:

Tabla IV. Codificación de la evidencialidad en las variantes de fijo con más ocurrencias.

\begin{tabular}{|l|r|r|r|r|r|}
\cline { 2 - 6 } \multicolumn{1}{c|}{} & \multicolumn{2}{c|}{ Evidencia } & \multicolumn{3}{c|}{ Orientación } \\
\cline { 2 - 6 } \multicolumn{1}{c|}{} & $\begin{array}{c}\text { Sensorial } \\
\text { (directa) }\end{array}$ & $\begin{array}{c}\text { Cognitiva } \\
\text { (indirecta) }\end{array}$ & Presente & Pasado & Futuro \\
\hline De fijo & $28,78 \%$ & $71,21 \%$ & $36,61 \%$ & $35,6 \%$ & $27,77 \%$ \\
\hline De fijo que & & $100 \%$ & $39,02 \%$ & $36,58 \%$ & $24,39 \%$ \\
\hline A punto fixo/fijo & $62,46 \%$ & $37,53 \%$ & $64,14 \%$ & $31,09 \%$ & $4,77 \%$ \\
\hline Ser fixo/fijo que & $4,54 \%$ & $95,45 \%$ & $45,45 \%$ & $50 \%$ & $4,55 \%$ \\
\hline Fijo que & & $100 \%$ & $17,07 \%$ & $36,58 \%$ & $46,34 \%$ \\
\hline A la fija & $20 \%$ & $80 \%$ & $20 \%$ & $25,71 \%$ & $54,28 \%$ \\
\hline Ir a la fija & $84,61 \%$ & $15,38 \%$ & $53,84 \%$ & $23,07 \%$ & $23,07 \%$ \\
\hline Ésa es la fija & $11,53 \%$ & $88,46 \%$ & $65,38 \%$ & & $34,61 \%$ \\
\hline
\end{tabular}

Los resultados del análisis demuestran que las formas que compiten en la expresión de los mismos valores poseen diferente función: la evidencia directa, que parte de la información sensorial que alguien, como testigo, ha vivido, se expresa mayoritariamente con la locución adverbial a punto fijo y con la locución verbal ir (alguien) a la fija; si se emplea un marcador discursivo para expresar evidencias directas, será de fijo (que podía actuar también como locución adverbial). Por su parte, las evidencias indirectas poseen formas variadas de expresión: las locuciones 
conjuntivas de fijo que y fijo que están especializadas en mostrar este modo de acceso a la información, pero en fijo que esa evidencia indirecta se realiza mayoritariamente por conjeturas $(85,36 \%)$, mientras que de fijo que puede expresar los tres tipos de evidencia cognitiva (inferencias, razonamientos y conjeturas); la estructura ser fixolfijo que, la locución adverbial a la fija, el marcador discursivo de fijo y la expresión ésa es la fija también manifiestan el modo cognitivo de acceso a la información de forma recurrente.

En cuanto a la orientación del mensaje, mientras que algunas marcas no presentan preferencias especiales en este sentido (de fijo, de fijo que), se observa que $a$ punto fijo, ir a la fija y ésa es la fija se utilizan principalmente orientadas al presente, a la fija muestra una clara disposición a la orientación futura, ser fixolfijo que se emplea para orientar el compromiso del hablante al pasado y al presente, y fijo que se orienta al futuro y al pasado.

De esta manera, si se atiende a las formas de uso general, no se observa una superposición de funciones para la expresión de los valores evidenciales en contextos concretos. Así, con respecto a las locuciones adverbiales, utilizadas preferentemente pospuestas al verbo, a punto fijo se especializa en reflejar la actitud del hablante en primera persona y evidencias sensoriales con verbos de conocimiento y elementos de polaridad negativa, mientras que de fijo abarca la expresión de evidencias indirectas por conjetura en contextos de condicionalidad y futuridad sobre todo; además, es la forma más empleada en español (por fijo también presenta estos valores, pero apenas se registra en diez ocasiones), de ahí que se haya ampliado su uso a la función de marcador del discurso, función en la que no compite con ninguna variante (solo es fijo se presenta mayoritariamente como marcador, pero tiene escaso uso). En cuanto a las locuciones conjuntivas, se usan principalmente en posiciones iniciales para mostrar conjeturas del hablante en tercera persona, pero los datos revelan que de fijo que y ser fijo que aparecen más frecuentemente en contextos condicionales, mientras que fijo que prefiere contextos futuros; de entre ellas, además, de fijo que es la más frecuente, ser fijo que está en desuso y fijo que parece estar imponiéndose en la oralidad por ser más breve y directa que las anteriores.

Las voces marcadamente dialectales tienen una frecuencia menor que las anteriores; de hecho, de las locuciones adverbiales en fija, en fijo y de fija y de las locuciones conjuntivas correspondientes en fija que, en fijo que y de fija que, apenas se cuenta con 15 ocurrencias en total, lo que impide emitir juicios concluyentes sobre su uso. A diferencia de las anteriores, a la fija tiene más éxito, se emplea preferentemente como locución adverbial y en contextos semejantes a de fijo, pero se documenta únicamente en Uruguay y Argentina. Además, en Colombia y Argentina también se registra la locución verbal ir alguien a la fija, que se ha creado de manera exclusiva para la expresión del valor 'ir sobre seguro' y muestra evidencias directas de tipo sensorial. 
Por último, queda por señalar las expresiones fijas estalesa es la fija, que se utilizan entre pausas, la primera más orientada a que el hablante muestre su punto de vista subjetivo sobre una expectativa personal que acaba haciéndose cierta y la segunda, más coloquial, para expresar la certeza de lo afirmado por otro interlocutor en contextos dialógicos.

En suma, las variantes léxicas de fijo constituyen una rica familia de términos que se agrupan en un conjunto diferenciado en distintos niveles de carácter continuo atendiendo a diversos parámetros: la productividad, la extensión geográfica, el registro y el periodo temporal en el que se han empleado.

\section{REFERENCIAS}

Bermúdez, Fernando W. (2005). Evidencialidad. La codificación lingüística del punto de vista. Tesis de doctorado. Estocolmo, Suecia: Universidad de Estocolmo. Disponible en http://su.diva-portal.org/smash/get/diva2:199511/FULLTEXT01. [Consulta: 11/10/2016].

Briz, Antonio, Pons, Salvador y Portolés, José (coords.). (2008). Diccionario de partículas discursivas del español. Disponible en http://www.dpde.es. [Consulta: $8 / 8 / 2016]$.

Cifuentes Honrubia, José L. (2018). Construcciones con clítico femenino fosilizado. Madrid, España: Verbum.

Company Company, Concepción. (2004). ¿Gramaticalización o desgramaticalización? Reanálisis y subjetivización de verbos como marcadores discursivos en la historia del español. RFE, 84/1, 29-66.

Cornillie, Bert. (2016). Acerca de la locución epistémica tal vez en el siglo de las Luces: innovación y especialización. En Martha Guzmán Riverón y Daniel M. Sáez (eds.) Márgenes y centros en el español del siglo XVIII. Valencia, España: Tirant Humanidades, 183-199. Disponible en https://lirias.kuleuven.be/ handle/123456789/375412. [Consulta: 4/12/2016].

Corominas, Joan y Pascual, José A. (1980). Diccionario crítico-etimológico castellano e hispánico. Madrid, España: Gredos.

Cuervo, Rufino J. (1998). Diccionario de construcción y régimen de la lengua castellana. Barcelona, España: Editorial Herder.

Davies, Mark. [en línea]. Corpus del español. Disponible en http://www.corpusdelespanol.org. [Consulta: 1/2/2017 - 30/7/2017].

Delbecque, Nicole. (2009). Acerca de la relación entre cierto y seguro. En Montserrat Veyrat Rigat y Enric Serra Alegre (eds.) La Lingüistica como reto epistemológico y como acción social. Estudios dedicados al Profesor Ángel López García con ocasión de su sexagésimo aniversario. Madrid, España: Arco Libros, 629-644. 
Gutiérrez Cuadrado, Juan (dir.). (1996). Diccionario Salamanca de la lengua española. Madrid, España: Santillana y Universidad de Salamanca.

Haiman, John. (1994). Ritualization and the development of language. En William Pagliuca (ed.) Perspectives on Grammaticalization. Amsterdam/Philadelphia, Países Bajos/Estados Unidos: John Benjamins, 3-28.

Lakoff, George y Johnson, Mark. (1980). Metaphors we live by. Chicago, Estados Unidos: The University of Chicago Press.

Lavale-Ortiz, Ruth M. [en prensa]. A cognitive approach to the grammaticalization of the epistemic marker fijo. En Jorge Fernández Jaén y Herminia Provencio Garrigós (eds.) Historical Linguistics. Current Theories and Applications. Amsterdam/Philadelpia, Alemania/Estados Unidos: John Benjamins.

Narrog, Heiko. (2017). Three types of subjectivity, three types of intersubjectivity, their dynamization and a synthesis. En Daniel Van Olmen, Hubert Cuyckens y Lobke Ghesquière (eds.) Aspects of Grammaticalization. (Inter)Subjectification and Directionality. Berlin/Boston, Alemania/Estados Unidos: Mouton de Gruyter, 19-46.

RAE, Real Academia Española. (2001). Diccionario de la lengua española. Madrid, España: Espasa.

RAE, Real Academia Española. (2009). Nueva gramática de la lengua española. Madrid, España: Espasa.

RAE, Real Academia Española. (2014). Diccionario de la lengua española. Madrid, España: Espasa.

RAE, Real Academia Española. Banco de datos (CORDE) [en línea]. Corpus diacrónico del español. Disponible en http://www.rae.es. [Consulta: 1/8/2016 - 30/7/2017].

RAE, Real Academia Española. Banco de datos (CORPES) [en línea]. Corpus del español del siglo XXI. Disponible en http://www.rae.es. [Consulta: 1/8/2016 - 30/7/2017].

RAE, Real Academia Española. Banco de datos (CREA) [en línea]. Corpus de referencia del español actual. Disponible en http://www.rae.es. [Consulta: 1/8/2016 - 30/7/2017].

RAE, Real Academia Española. [en línea]. Nuevo tesoro lexicográfico de la lengua española. Disponible en http://ntlle.rae.es/ntlle/SrvltGUILoginNtlle. [Consulta: $1 / 8 / 2016-31 / 8 / 2016]$.

Rodríguez-Espiñeira, María-José. (2010). Modalidad, gramática y discurso: posible, probable y sus antónimos. En María-José Rodríguez-Espiñeira (ed.) Adjetivos en discurso. Emociones, certezas, posibilidades y evidencias. Santiago de Compostela, España: Universidade de Santiago de Compostela, 181-248.

Santos Río, Luis. (2003). Diccionario de partículas. Salamanca, España: Luso-Española de Ediciones. 
Traugott, Elizabeth C. (1995). Subjectification in grammaticalisation. En Dieter Stein y Susan Wright (eds.) Subjectivity and Subjectivisation: Linguistic Perspectives. Cambridge, Reino Unido: Cambridge University Press, 31-54. 